\title{
Intracranial Arteries in Individuals with the Elastin Gene Hemideletion of Williams Syndrome
}

\author{
D.P. Wint, J.A. Butman, J.C. Masdeu, A. Meyer-Lindenberg, C.B. Mervis, D. Sarpal, C.A. Morris, and K.F. Berman
}

\begin{abstract}
BACKGROUND AND PURPOSE: Williams syndrome, a rare genetic disorder with a striking neurobehavioral profile characterized by extreme sociability and impaired visuospatial construction abilities, is caused by a hemideletion that includes the elastin gene, resulting in frequent supravavular aortic stenosis and other stenotic arterial lesions. Strokes have been reported in Williams syndrome. Although the extracranial carotid artery has been studied in a sample of patients with Williams syndrome, proximal intracranial arteries have not.
\end{abstract}

MATERIALS AND METHODS: Using MRA, we studied the intracranial vessels in 27 participants: 14 patients with Williams syndrome (age range, $18-44$ years; mean age, $27.3 \pm 9.1 ; 43 \%$ women) and 13 healthy control participants with similar age and sex distribution (age range, 22-52 years; mean age, $33.4 \pm 7.6 ; 46 \%$ women). All participants with Williams syndrome had hemideletions of the elastin gene. Blinded to group allocation or to any other clinical data, a neuroradiologist determined the presence of intracranial vascular changes in the 2 groups.

RESULTS: The Williams syndrome group and the healthy control group had similar patency of the proximal intracranial arteries, including the internal carotid and vertebral arteries; basilar artery; and stem and proximal branches of the anterior cerebral artery, MCA, and posterior cerebral arteries. The postcommunicating segment of the anterior cerebral artery was longer in the Williams syndrome group.

CONCLUSIONS: Despite the elastin haploinsufficiency, the proximal intracranial arteries in Williams syndrome preserve normal patency.

ABBREVIATIONS: $\mathrm{ACA}=$ anterior cerebral artery; SVAS $=$ supravalvular aortic stenosis; SVPS $=$ supravalvular pulmonic stenosis

W illiams syndrome (On-line Mendelian Inheritance in Man number, 194050) is a multisystem disorder characterized neurologically by remarkable hypersociability along with a distinct deficit in visuospatial construction abilities. ${ }^{1-3}$ Intellectual ability ranges from average for the general population to severe disability, with most people performing in the borderline to mod-

Received February 8, 2013; accepted after revision April 8.

From the Section on Integrative Neuroimaging, Clinical Brain Disorders Branch (D.P.W., J.C.M., A.M.-L., D.S., K.F.B.), National Institute of Mental Health, and Radiology and Imaging Sciences, Warren G. Magnuson Clinical Center (J.A.B.), Intramural Research Program, National Institutes of Health, Bethesda, Maryland; Neurodevelopmental Sciences Laboratory (C.B.M.), Department of Psychological and Brain Sciences, University of Louisville, Louisville, Kentucky; and Department of Pediatrics (C.A.M.), University of Nevada School of Medicine, Las Vegas, Nevada.

D.P.W. is currently at the Cleveland Clinic Lou Ruvo Center for Brain Health, Las Vegas, Nevada. A.M.-L. is currently at the Central Institute of Mental Health, Mannheim, Germany. D.S. is currently at the North Shore-LIJ Health System, Glen Oaks, New York.

This work was funded by the NIMH Intramural Research Program, Bethesda, Maryland, and by a grant from the National Institute of Neurological Disorders and Stroke (R01 NS35102) to C.B.M.

Please address correspondence to Karen F. Berman, MD, 10 Center Dr 3C111, Bethesda, MD 20892; e-mail: bermank@mail.nih.gov

- Indicates open access to non-subscribers at www.ajnr.org

三 Indicates article with supplemental on-line table.

http://dx.doi.org/10.3174/ajnr.A3641 erate range. ${ }^{2}$ With an estimated prevalence of 1 in 7500 live births, ${ }^{4}$ Williams syndrome results from a hemizygous contiguous microdeletion on chromosome 7. The missing band, an approximately 1.6-megabase span at 7q11.23, codes for more than 20 proteins, including elastin. ${ }^{5}$

As a major component of distensible tissues such as the skin, lungs, and vascular walls, elastin plays an important role in normal physiologic functioning. ${ }^{6}$ Elastin deficiency results in fibroblast proliferation in arterial walls, ${ }^{7,8}$ leading to altered mural elasticity and macrostructural deformities, best described for the great arteries and heart. ${ }^{9,10}$ The reported prevalence of cardiovascular structural abnormalities in Williams syndrome hovers at approximately $75 \%$ $(70 \%-82 \%) .{ }^{11-13}$ Supravavular aortic stenosis (SVAS) and peripheral pulmonary artery stenosis are the most common cardiovascular deformities. ${ }^{11,14}$ Arterial narrowing may be isolated or may occur simultaneously in numerous locations, including the aortic arch; the descending aorta; and the pulmonary, coronary, renal, and mesenteric arteries. ${ }^{3}$ Aneurysmal dilation may occur after stent placement or other procedures to correct the stenotic lesions, ${ }^{15}$ or may rarely manifest spontaneously, particularly in adults. ${ }^{16}$

A widespread misunderstanding, derived from the distribution of arterial involvement in giant-cell arteritis, ${ }^{17}$ holds that the 
intracranial arteries do not have elastic layers in their walls. In reality, although the external elastic lamina, between the media and adventitia, is lost a few millimeters after the large arteries perforate the dura to enter the cranial cavity, the internal elastic lamina, in the media, is present. Therefore, the elastin gene hemideletion in Williams syndrome could be associated with arterial stenosis or dilation and compromised hemodynamic function. ${ }^{17,18}$ However, only a few case reports have documented cerebrovascular disease in Williams syndrome. They include spontaneous dissection of the internal carotid artery, leading to an MCA infarction, in an adult ${ }^{19} ; 3$ patients with striatocapsular infarctions: an adult ${ }^{20}$ and a child ${ }^{21}$ with clean cerebral vessels on angiography, and a child with stenosis of the supraclinoid carotid and $\mathrm{M} 1$ segment of the $\mathrm{MCA}^{22}$; and narrowing of proximal intracranial arteries in 3 children and a young adult with multiple cerebral infarcts. ${ }^{23-25}$ In addition, an adult had a cardiogenic stroke after a myocardial infarction. ${ }^{26}$ Finally, intracerebral hemorrhages, possibly resulting from aneurysmal arteriolar thinning, have been documented in 2 cases. ${ }^{27,28}$ The extracranial carotid arteries have been studied in Williams syndrome with sonography and have been found to lack stenotic or aneurysmatic lesions but have been found to have increased media thickness. ${ }^{29}$ However, although the potential for intracranial cerebral arterial abnormalities in Williams syndrome would constitute a substantial clinical risk factor, the proximal intracranial arterial tree has not been studied systematically in this disorder by use of a prospective design in a population without acute symptoms. To address this gap in knowledge, we used MRA to determine the prevalence of anomalies of the proximal intracranial arterial tree in adults with Williams syndrome.

\section{MATERIALS AND METHODS \\ Participant Selection and Genetic Testing}

Study procedures were approved by the CNS Institutional Review Board of the National Institutes of Health. Participants gave written consent after being informed of the nature and purposes of the study. Fourteen normal-IQ white adults with Williams syndrome gave written consent to participate after being informed of the nature and purposes of the research and were enrolled in the study. All of the participants in this group exhibited the physical features and cognitive profile typical of Williams syndrome, were in good physical health, and did not take any psychotropic medication. Genetic testing had been performed by use of fluorescent in situ hybridization according to standard procedures. ${ }^{30}$ Thirteen of these participants had the classic 1.6-megabase hemideletion in $7 \mathrm{q} 11.23,{ }^{1}$ and 1 participant had a shorter hemideletion that included the gene coding for elastin. The MR imaging data from 13 healthy control participants, who were not receiving medications, were used for comparison. The control participants were recruited by advertisement and were matched for sex, age, and IQ to the group with Williams syndrome. All study participants were right-handed.

\section{History and Examination}

The participants and their parents provided histories of medical and psychiatric diagnoses and treatments, which were supplemented with medical record review. Each participant also under- went physical and neurologic examination on entry into the study.

\section{Image Acquisition}

MR imaging was performed on a Signa 1.5T scanner (GE Healthcare, Milwaukee, Wisconsin) at the National Institutes of Health Nuclear Magnetic Resonance Research Center, by use of a standard head coil. Six T1WIs (TR, 12 ms; TE, $5.2 \mathrm{~ms}$; FOV, $24 \mathrm{~mm}$; resolution, $0.94 \times 0.94 \times 1.2 \mathrm{~mm}$ ) were registered and averaged to create a high-resolution structural image for each participant. The major intracranial arteries were imaged by $3 \mathrm{D}$ time-of-flight MRA, with the following parameters: field of view, $22 \mathrm{~cm}$; TR, 35 $\mathrm{ms}$; TE, $3.4 \mathrm{~ms}$; flip angle, $20^{\circ}$; section thickness, $1.4 \mathrm{~mm}$; and acquisition time, 6 minutes.

\section{Image Analysis}

Images were processed from DICOM format on an Advantage Workstation (AW 4.1; GE Healthcare). Brain MR images were reformatted into double-oblique views to permit analysis of the cerebral midline. Vessels in the circle of Willis were partitioned from the rest of the MRA to increase signal-to-noise ratio. The arteries evaluated included the intracranial portion of the internal carotid and vertebral arteries; basilar artery; and stem and proximal branches of the anterior cerebral, middle cerebral, and posterior cerebral arteries. A neuroradiologist (J.A.B.) with expertise in the interpretation of high-resolution MR imaging and MRA performed qualitative analyses of the images, by using maximumintensity projection reconstructions. He was blinded to the name, sex, genetic/diagnostic status, physical appearance, and cognitive performance of the participants. Any vascular abnormalities, including stenosis and vasospasm, as well as vascular variants were recorded.

\section{Statistical Analyses}

We did not make any assumptions as to the direction of the findings and therefore used 2-tailed statistics. Nominal data were analyzed with the Fisher exact test; age was analyzed with the Student $t$ test. Correlations were explored with the nonparametric Spearman correlation.

\section{RESULTS \\ Demographics}

Age and sex of the participants were similar in the Williams syndrome and control groups. The average age of the 14 participants with Williams syndrome was $27.3 \pm 9.1$ years, compared with $33.4 \pm 7.6$ years for the 13 participants in the control group $(P=.11)$. Each group included 6 women $(P=.58)$.

\section{Medical Histories}

Medical findings in participants with Williams syndrome are detailed in Table 1 . A total of $12(86 \%)$ had a history of at least 1 cardiovascular illness. SVAS was present in 9 (64\%) and supravavular pulmonic stenosis (SVPS) in 3 (21\%). Mitral valve abnormalities were recorded in 3 (21\%). Four participants (29\%) had histories of hypertension. Gastrointestinal tract difficulties, present in 11 (79\%) participants with Williams syndrome, included hernias, constipation, diverticular disease, and rectal 
Table 1: Medical findings in participants with Williams syndrome

\begin{tabular}{|c|c|c|c|c|c|c|}
\hline \multirow[b]{2}{*}{ Participant } & \multirow{2}{*}{$\begin{array}{l}\text { Age } \\
\text { (y) }\end{array}$} & \multirow{2}{*}{$\begin{array}{l}\text { Pulse } \\
\text { (bpm) }\end{array}$} & \multicolumn{2}{|c|}{$\begin{array}{l}\text { Blood Pressure } \\
(\mathrm{mm} \mathrm{Hg})\end{array}$} & \multirow[b]{2}{*}{ Medical History } & \multirow[b]{2}{*}{ Cardiovascular History } \\
\hline & & & Systolic & Diastolic & & \\
\hline 1 & 18 & 84 & 130 & 90 & Inguinal hernia & Hypertension \\
\hline 2 & 18 & & Not availat & & Hypercalcemia, joint limitation & SVAS \\
\hline 3 & 18 & 72 & 90 & 70 & $\begin{array}{l}\text { Chronic otitis media, hip subluxation, } \\
\text { kyphosis, constipation }\end{array}$ & $\begin{array}{l}\text { Ventricular septal defect, SVPS, prolonged } \\
\text { Q-T interval }\end{array}$ \\
\hline 4 & 19 & 64 & 110 & 80 & Constipation & Negative \\
\hline 5 & 22 & 64 & 130 & 80 & $\begin{array}{l}\text { Chronic otitis media, scoliosis, rectal } \\
\text { prolapse, constipation }\end{array}$ & Mitral valve prolapse, hypertension \\
\hline 6 & 22 & & Not availat & & $\begin{array}{l}\text { Left conductive hearing loss, chronic } \\
\text { otitis media, joint limitation }\end{array}$ & SVAS, mitral valve prolapse \\
\hline 7 & 23 & 64 & 120 & 60 & $\begin{array}{l}\text { Inguinal hernia, umbilical hernia, joint } \\
\text { impairment }\end{array}$ & SVAS, SVPS, mitral valve prolapse \\
\hline 8 & 24 & 80 & 130 & 80 & $\begin{array}{l}\text { Chronic otitis media, inguinal hernia, } \\
\text { joint impairment }\end{array}$ & $\begin{array}{l}\text { SVAS, peripheral pulmonary stenosis, } \\
\text { hypertension }\end{array}$ \\
\hline 9 & 29 & 72 & 120 & 92 & Hypercalcemia & SVAS \\
\hline 10 & 30 & 76 & 120 & 70 & Inguinal hernia & SVAS, SVPS \\
\hline 11 & 33 & 68 & 165 & 100 & Constipation, inguinal hernia & SVAS, hypertension, renal artery stenosis \\
\hline 12 & 37 & 100 & 110 & 70 & Diverticulitis, constipation & SVAS, carotid bruit \\
\hline 13 & 44 & 62 & 120 & 91 & $\begin{array}{l}\text { Hypercalcemia, kyphosis, chronic } \\
\text { abdominal pain, constipation }\end{array}$ & SVAS \\
\hline 14 & 45 & 96 & 130 & 85 & Diverticulitis & No history of hypertension \\
\hline
\end{tabular}
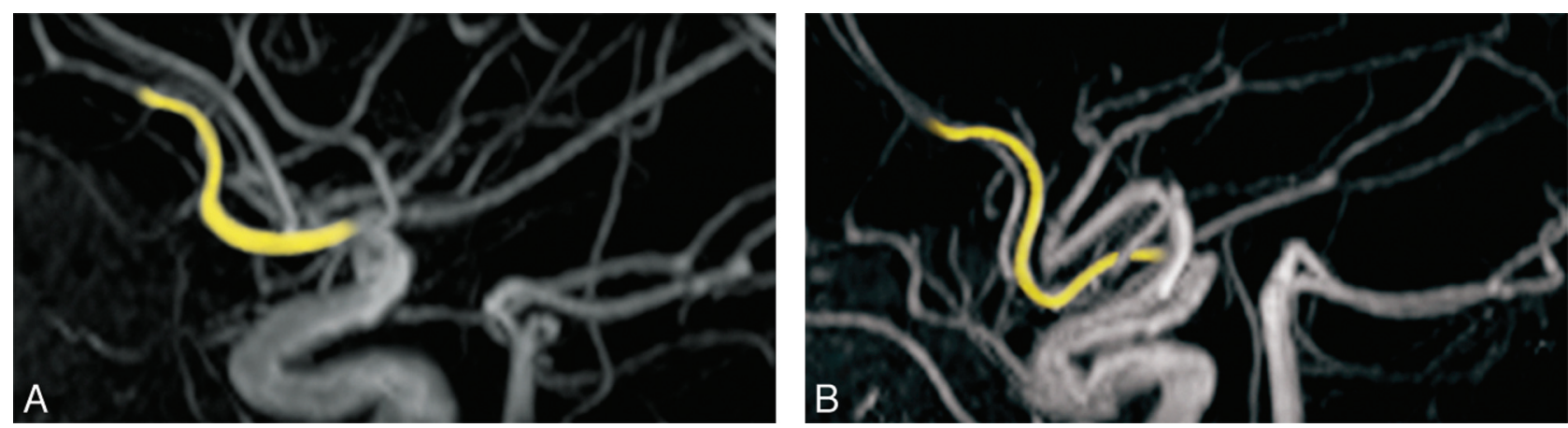

FIGURE. Anterior cerebral artery configuration in Williams syndrome. MRA from a normally developing person (A) and a participant with Williams syndrome $(B)$ showing elongation of the postcommunicating segment of the anterior cerebral artery in the participant with Williams syndrome.

prolapse. Other than the cognitive changes reported elsewhere, ${ }^{1,31}$ the most common neurologic abnormalities were clumsy or uncoordinated gait $(79 \%)$ and poor cerebellar function $(71 \%)$.

\section{Imaging Findings}

MR imaging and MRA findings are listed in the On-line Table.

\section{Structural MR Images}

There was a tendency toward a higher prevalence of atypical gross structural findings in the brains of the Williams syndrome group. Eight participants with Williams syndrome vs 4 control participants had at least 1 morphologic anomaly $(P=.252)$. The most frequently noted neuroanatomic finding was a small or unusually shaped corpus callosum, which was present in 6 members of the Williams syndrome group and in 2 of the control particpants $(P=.209)$. In 5 of the participants with Williams syndrome who had callosal anomalies, the irregularity was in the anterior portion (rostrum or genu) of the corpus callosum. Other findings in the Williams syndrome group were descended cerebellar tonsils and a thickened calvarium. Two control participants were thought to have small-appearing cerebellar hemispheres.

\section{MRA}

Most importantly, there were no stenoses or other hemodynamically significant lesions in either group. Enlarged collaterals were not noted. However, incidental anomalies on MRA were significantly more frequent in the Williams syndrome group. The Figure depicts a specific variation in the course of the anterior cerebral artery (ACA) that was noted only in members of the Williams syndrome group. Typically, the A2 postcommunicating segment of the ACA courses horizontally and then ascends along the genu of the corpus callosum before dividing into the callosomarginal and pericallosal arteries. In 6 of the participants with Williams syndrome, but in none of the matched control participants $(P=$ .016), A2 deviated inferiorly before turning toward the callosal genu. No correlation was observed between this ACA variant and the presence of either hypertension or SVAS-SVPS. The other MRA findings in participants with Williams syndrome and in the control group are listed in the On-line Table. 
Table 2: Prevalence of medical conditions in patients with Williams syndrome

\begin{tabular}{|c|c|c|c|c|}
\hline \multirow[b]{3}{*}{ Medical Condition } & \multicolumn{4}{|c|}{ Study } \\
\hline & \multicolumn{2}{|c|}{ Wint et $\mathrm{al}^{\mathrm{a}}(n=14)$} & \multirow{2}{*}{$\frac{\operatorname{AAP}^{\mathrm{b}}(n=315)}{\%}$} & \multirow{2}{*}{$\frac{\text { Cherniske et al }{ }^{c}(n=20)}{\%}$} \\
\hline & $n$ & $\%$ & & \\
\hline Cardiovascular & 12 & 86 & 80 & 70 \\
\hline SVAS & 9 & 64 & 75 & 65 \\
\hline SVPS & 3 & 21 & 25 & 15 \\
\hline Peripheral pulmonary stenosis & 1 & 7 & 50 & - \\
\hline Mitral valve prolapse & 3 & 21 & - & 15 \\
\hline Other & 1 & 7 & - & 35 \\
\hline Hypertension & 4 & 29 & 50 & 60 \\
\hline Gastrointestinal & 11 & 79 & - & 75 \\
\hline Inguinal hernia & 5 & 36 & 40 & - \\
\hline Constipation & 7 & 50 & 40 & 25 \\
\hline Diverticular disease & 3 & 21 & 30 & 40 \\
\hline Rectal prolapse & 1 & 7 & 15 & - \\
\hline \multicolumn{5}{|l|}{ Neurologic } \\
\hline Hyperreflexia & 7 & 50 & 75 & 65 \\
\hline Gait disturbance & 11 & 79 & 60 & 70 \\
\hline Ataxia & 10 & 71 & - & - \\
\hline Skeletal & 6 & 43 & 50 & - \\
\hline Spinal & 3 & 21 & 60 & 60 \\
\hline Peripheral & 5 & 36 & 50 & 55 \\
\hline Chronic otitis & 4 & 29 & 50 & - \\
\hline
\end{tabular}

Note:- This is a comparison of the prevalence of medical problems in this study's participants with those reported in 2 large studies of Williams syndrome. The number of participants with each condition is listed in the leftmost column.

a Present study.

${ }^{\mathrm{b}}$ American Academy of Pediatrics, 2001. ${ }^{32}$

${ }^{c}$ Cherniske et al, 2004. ${ }^{33}$

\section{DISCUSSION}

In this first systematic study of cerebral vasculature in patients with Williams syndrome, we have documented that, except for a minor difference in the anatomic configuration of the ACA, the major intracranial arteries in Williams syndrome were similar to those of matched healthy control participants. Because the resolution of MRA does not allow analysis of submillimeter arterial vessels, such as those that penetrate the cerebral cortex, a possibility still remains that elastin deficiency could affect the patency of those arteries. A strength of our study was that it included adults with Williams syndrome, rather than children, allowing us to explore the end result of possible developmental changes during childhood and adolescence. However, it is important to stress that our study was cross-sectional; it did not allow us to predict arterial changes in later adulthood. It could be argued that our sample was skewed, because it included only adults with a normal IQ. However, the cardiovascular findings in our sample (Table 1) are essentially indistinguishable from those of the general Williams syndrome population (Table 2). ${ }^{1-13}$ The relatively small incidence of peripheral pulmonary stenosis in our sample of adult patients with Williams syndrome reflects that peripheral pulmonary artery stenosis is often present in infancy and usually improves with time. ${ }^{32}$ Therefore, peripheral pulmonary artery stenosis is less frequent in our sample of adults than in the much younger sample from the American Academy of Pediatrics (Table 2). Furthermore, the prevalence of various medical illnesses in our participants is comparable to the corresponding prevalence reported in previous studies of children and adults with Williams syndrome that included the full range of intellectual ability associated with this syndrome (Table 2), ${ }^{32,33}$ suggesting that the cerebrovascular findings in our study may be generalized to the wider
Williams syndrome population with no presenting neurologic complaints.

Careful qualitative analysis of MRA for each participant revealed no lesions of hemodynamic significance in the large intracranial arteries, an important negative finding in a population that, by virtue of cardiovascular anomalies and hypertension, could be at elevated risk for stroke. Although only approximately 12 cases of stroke in patients with Williams syndrome have been reported in the literature, the true incidence of stroke in this population is unknown. ${ }^{34}$ Our findings suggest that most large-artery strokes in Williams syndrome may be related to mechanisms other than significant intracranial arterial involvement. A subset of recorded strokes may be attributable to cardiac or aortic risk factors, which are present in a high proportion of people with Williams syndrome and were documented in some instances of stroke in this syndrome. ${ }^{26}$ The association with extracranial disorder is likely to occur in cases where no cerebrovascular abnormalities were detected by angiography. ${ }^{20,21}$ Even in the few stroke cases in which stenotic lesions were documented in the major intracranial vessels, ${ }^{22-24}$ the possibility of embolism with recanalization cannot be completely ruled out. In some patients, stroke onset was clearly timed to surgical procedures for the correction of aortic disease. ${ }^{25}$ Furthermore, the presence of small distal microinfarcts in the brain of a person with Williams syndrome studied at autopsy suggests that cardioarterial disease in this population may predispose to embolic infarction. ${ }^{35}$

Although by using MRA we did not detect hemodynamically significant lesions in our participants with Williams syndrome, we encountered an atypical ACA morphologic feature that was common and specific to Williams syndrome. The usual course of the subgenual ACA was altered in 6 members of the Williams syndrome group by an inferiorly directed "loop" of A2 just proximal to the upward turn of the ACA (Figure). The unusual morphologic pattern of A2 may be a result of the same mechanism that is thought to cause SVAS and SVPS, namely, focal overproliferation of the arterial laminar cells. In the case of the ACA, excessive growth would necessarily impel a downward extension. It is also possible that the ACA develops normally, but A2 is displaced inferiorly because the ACA is "too long" for the unusually short and flat cerebrum and callosum that have been observed in this and other studies of Williams syndrome. ${ }^{36}$

\section{CONCLUSIONS}

In summary, by using MRA we did not detect stenoses or other hemodynamically significant lesions of the proximal intracranial arteries in Williams syndrome, attended by elastin deficiency and stenotic lesions in other arteries. However, most of the partici- 
pants with Williams syndrome and, therefore, elastin haploinsufficiency had unusual cerebrovascular morphologic features. Most of the characteristics involved an elongation of the postcommissural segment of the ACA.

Disclosures: Dylan Wint-RELATED: Support for Travel to Meetings for the Study or Other Purposes: National Institutes of Health.* Joseph Masdeu—RELATED: Grant: National Institutes of Health Intramural Research Program*; UNRELATED: Royalties: Lippincott Williams and Wilkins, Elsevier, Comments: Books and book chapters; Travel/Accommodations/Meeting Expenses Unrelated to Activities Listed: American Academy of Neurology; Other: American Society of Neuroimaging, Comments: Editorship of the Journal of Neuroimaging. Andreas Meyer-Lindenberg-UNRELATED: Board Membership: Advisory Boards: AstraZeneca, Hoffmann-La Roche, Outcome Europe Sarl; Consultancy: Alexza Pharmaceuticals; Payment for Lectures (including service on speaker bureaus): Bristol-Myers Squibb, H. Lundbeck A/S, Janssen Cilag, Lilly Deutschland GmbH, Pfizer Pharma GmbH, Servier. Caroyln Mervis—RELATED: Grant: NIH*; Support for Travel to Meetings for the Study or Other Purposes: NIH.* Colleen Morris—RELATED: Grant: University of Louisville, ${ }^{*}$ Comments: This was a subcontract on a grant to Dr. Carolyn Mervis from NINDS. *Money paid to institution.

\section{REFERENCES}

1. Meyer-Lindenberg A, Kohn P, Mervis CB, et al. Neural basis of genetically determined visuospatial construction deficit in Williams syndrome. Neuron 2004;43:623-31

2. Mervis CB, John AE. Cognitive and behavioral characteristics of children with Williams syndrome: implications for intervention approaches. Am J Med Genet C Semin Med Genet 2010;154C:229-48

3. Pober BR. Williams-Beuren syndrome. N Engl J Med 2010; 362:239-52

4. Strømme P, Bjørnstad PG, Ramstad K. Prevalence estimation of Williams syndrome. J Child Neurol 2002;17:269-71

5. Morris CA, Thomas IT, Greenberg F. Williams syndrome: autosomal dominant inheritance. Am J Med Genet 1993;47:478-81

6. Kielty CM, Sherratt MJ, Shuttleworth CA. Elastic fibres. J Cell Sci 2002;115:2817-28

7. O'Connor WN, Davis JB Jr, Geissler R, et al. Supravalvular aortic stenosis. Clinical and pathologic observations in six patients. Arch Pathol Lab Med 1985;109:179-85

8. Li DY, Brooke B, Davis EC, et al. Elastin is an essential determinant of arterial morphogenesis. Nature 1998;393:276-80

9. Lacolley P, Boutouyrie P, Glukhova M, et al. Disruption of the elastin gene in adult Williams syndrome is accompanied by a paradoxical reduction in arterial stiffness. Clin Sci (Lond) 2002;103:21-29

10. Urbán Z, Riazi S, Seidl TL, et al. Connection between elastin haploinsufficiency and increased cell proliferation in patients with supravalvular aortic stenosis and Williams-Beuren syndrome. Am J Hum Genet 2002;71:30-44

11. Collins RT 2nd, Kaplan P, Somes GW, et al. Long-term outcomes of patients with cardiovascular abnormalities and Williams syndrome. Am J Cardiol 2010;105:874-78

12. Yau EK, Lo IF, Lam ST. Williams-Beuren syndrome in the Hong Kong Chinese population: retrospective study. Hong Kong Med J 2004;10:22-27

13. Del Pasqua A, Rinelli G, Toscano A, et al. New findings concerning cardiovascular manifestations emerging from long-term follow-up of 150 patients with the Williams-Beuren-Beuren syndrome. Cardiol Young 2009;19:563-67

14. Ahmad Z, Vettukattil J. Pulmonary artery diverticulum: an angiographic marker for Williams syndrome. Pediatr Cardiol 2010;31: 611-14
15. Geggel RL, Gauvreau K, Lock JE. Balloon dilation angioplasty of peripheral pulmonary stenosis associated with Williams syndrome. Circulation 2001;103:2165-70

16. McKenna AJ, Craig B, Graham AN. Williams syndrome in an adult. J Card Surg 2010;25:339-42

17. Wilkinson IM, Russell RW. Arteries of the head and neck in giant cell arteritis. A pathological study to show the pattern of arterial involvement. Arch Neurol 1972;27:378-91

18. Ortiz PP, Sarrat R, Daret D, et al. Elastin variations implicating in vascular smooth muscle cells phenotype in human tortuous arteries. Histol Histopathol 2000;15:95-100

19. Vanacker $P$, Thijs V. Spontaneous cervical artery dissection in adult Williams syndrome. Cerebrovasc Dis 2009;27:309-10

20. Wollack JB, Kaifer M, LaMonte MP, et al. Stroke in Williams syndrome. Stroke 1996;27:143-46

21. Lee WD, Hsu JJ, Huang FC, et al. Ischemic stroke in WilliamsBeuren syndrome: a case report. Kaohsiung J Med Sci 2009;25: 212-16

22. Soper R, Chaloupka JC, Fayad PB, et al. Ischemic stroke and intracranial multifocal cerebral arteriopathy in Williams syndrome. J Pediatr 1995; 126:945-48

23. Kaplan P, Levinson M, Kaplan BS. Cerebral artery stenoses in Williams syndrome cause strokes in childhood. J Pediatr 1995; 126:943-45

24. Ardinger RH, Jr, Goertz KK, Mattioli LF. Cerebrovascular stenoses with cerebral infarction in a child with Williams syndrome. Am J Med Genet 1994;51:200-02

25. Sim YW, Lee MS, Kim YG, et al. Unpredictable postoperative global cerebral infarction in the patient of Williams syndrome accompanying Moyamoya disease. J Korean Neurosurg Soc 2011;50:256-59

26. Blanc $F$, Wolff $V$, Talmant $V$, et al. Late onset stroke and myocardial infarction in Williams syndrome. Eur J Neurol 2006;13:e3-4

27. Kawai M, Nishikawa T, Tanaka M, et al. An autopsied case of Williams syndrome complicated by Moyamoya disease. Acta Paediatr Jpn 1993;35:63-67

28. Kalbhenn T, Neumann LM, Lanksch WR, et al. Spontaneous intracerebral hemorrhage and multiple infarction in Williams-Beuren syndrome. Pediatr Neurosurg 2003;39:335-38

29. Sadler LS, Gingell R, Martin DJ. Carotid ultrasound examination in Williams syndrome. J Pediatr 1998;132:354-56

30. Lowery MC, Morris CA, Ewart A, et al. Strong correlation of elastin deletions, detected by FISH, with Williams syndrome: evaluation of 235 patients. Am J Hum Genet 1995;57:49-53

31. Meyer-Lindenberg A, Hariri AR, Munoz KE, et al. Neural correlates of genetically abnormal social cognition in Williams syndrome. Nat Neurosci 2005;8:991-93

32. Committee on Genetics. American Academy of Pediatrics: Health care supervision for children with Williams syndrome. Pediatrics 2001;107:1192-204

33. Cherniske EM, Carpenter TO, Klaiman C, et al. Multisystem study of 20 older adults with Williams syndrome. Am J Med Genet 2004;131A:255-64

34. Beslow LA, Jordan LC. Pediatric stroke: the importance of cerebral arteriopathy and vascular malformations. Childs Nerv Syst 2010;26:1263-73

35. Galaburda AM, Bellugi UV. Multi-level analysis of cortical neuroanatomy in Williams syndrome. J Cogn Neurosci 2000;12 Suppl $1: 74-88$

36. Schmitt JE, Eliez S, Warsofsky IS, et al. Corpus callosum morphology of Williams syndrome: relation to genetics and behavior. Dev Med Child Neurol 2001;43:155-59 